ISSN 1112-9867

A vailable online at http://www.jfas.info

\title{
EFFECT OF 8-WEEK EXERCISEON IMPROVING THE STATIC AND DYNAMIC BALANCE OF SUPINATED FOOT
}

\author{
M. M. Mehrian, ${ }^{*}$ A. Sarshin ${ }^{1}$, H. Rostamkhani ${ }^{2}$ \\ ${ }^{1}$ The department of sport biomechanics, Faculty of Physical Education and sport sciences, Karaj \\ Branch, Islamic Azad University, Karaj, Iran \\ ${ }^{2}$ Department of sport physiology Faculty of Physical Education and sport sciences, Abhar \\ Branch, Islamic Azad University, Abhar, Iran
}

Published online: 15 May 2016

\begin{abstract}
Background: the supinated foot is one of the lower limb abnormalities that is associated with navicular drop and may be affected by leg muscles. The aim of this study was to investigate the effects of 8-week corrective exercises to improve static and dynamic balance of supinated foot.

Materials and methods: The current research is a quasi-experimental study, in which twenty 1825 male subjects that all suffer supinated leg were chosen purposefully into two groups (10) of experimental and control. Before the training program of supinated legs of navicular drop test subjects, static balance and dynamic balance was measured with a force platform. The experimental group carried out exercises program for 8 weeks with a frequency of three times a week on the area of weak muscles and stretched legs, and the control group were doing their usual activities. After 8 weeks of corrective exercises, static and dynamic balance and supinated leg were measured again. To analyze the data, independent t-test for changes between the group and dependent t-test for within-group changes were used.
\end{abstract}

Author Correspondence, e-mail: morteza.mansori405@yahoo.com doi: http://dx.doi.org/10.4314/jfas.v8i3s.273 
Findings: The results showed a significant increase in static balance (shifting the center of pressure, $p=0.011$ ), dynamic balance (time to stabilization in the lateral direction, $p=0.008$ ) as well as supinated leg $(\mathrm{p}=0.00)$ between pre-test and post-test experimental group. However, no significant differences in dynamic balance in the anterior-posterior direction $(p=0.2)$ in the experimental group were observed. In the control group variables during the study period, no significant difference was observed.

Conclusion: Using corrective exercises presented in this study, the static and dynamic balance level and navicular drop could be improved, and supinated foot deformity was corrected.

Keywords: corrective exercises, static balance, dynamic balance, supinated foot

\section{INTRODUCTION}

Supinated foot is a lower limb deformity that may cause damage $(6,7)$. This abnormality causes the ankle turn out and the navicular drop test subjects in this abnormality is less than 4 millimeters (8). The factors for this anomaly are tibia muscle tightness and muscle strain that leads to a supinated foot (4). This abnormality is generally because of inadequate muscles and joints function environmental reasons, as well as bad movement habits and it is possible to be modified through corrective exercises (3). Research findings show that supinated foot is a consequence of mechanical structure of foot and disturbance of sensory information may increase the likely of foot ankle injuries such as sprains ankle and knee injuries (1). On the other hand the balance is an important factor in many athletic skills, and its weakness is associated with a lot of injuries, instability, ankle and knee pain, osteoarthritis and ankle sprains (12). Proper training can improve the ability to maintain balance and postural control in individuals with different abilities and limitations (5). Balance is an important factor on every move and fitness and physical activity; balance is often used to measure the performance of lower limb (11). Abnormal foot structure can affect people's ability and performance (14). Practice is the most important factor in learning motor skills; at a later stage the quality of training and practice runs are important (10). The ultimate goal of the program of corrective exercises is to restore optimal body posture and correct distortions that can be caused by various factors. However, other objectives such as control and reduce pain, restore range of joint function, restore flexibility, muscular strength and endurance, balance and performance improvements are also included in the program of corrective exercises (4). In studying the literature it is less observed that a corrective exercise be offered to 
people with supinated abnormality and its effect on static and dynamic balance be measured. In this study, the exercise protocol was focused on the development and strengthening of the muscles of the posterior tibialsand elasticity of peroneal muscles, such that the impact of these exercises on improving static balance and supinated and supinated foot be evaluated.

\section{MATERIALS AND METHODS}

This study was an Impact Assessment quasi-experimental study. The research population was formed of 18 to 25-year-old male students Islamic Azad University of Yasouj. 20 subjects with navicular drop less than $4 \mathrm{~mm}$ were purposefully selected and randomly divided into two groups of 10 patients; one experimental group and one control group were considered. Subjects who were inone of the following conditionsexcluded from the study:

1- The history of lower extremity injury in the last 6 months.

2- The symptoms of lower extremity injury that need to have a rest.

3- Being professional athletes.

4- Do not have knees abnormalities.

In this study, in order to select supinated foot people, navicular drop test index (11) as described by Brady, was used (8). Navicular drop test was carried out by two raters. Navicular drop values, are valid and reliable clinical measures of supination feet $(9,13,15)$. Macpoyl et.al $(1996)$ mentioned the reliability of navicular drop as 0.94-0.98 (13). In order to find and mark Navi foot bumps, first subjects seated on a chair with knee angle of approximately 90 degrees, and two feet on the ground and the joint under Subtalar joint was in a natural state.Thigh movement was controlled manually by the experimenter.Normal status of under Subtalar joint is achieved by examiner rotating the ankle patio to the inside and outside, so that internal and external aspects could equally be touched. By putting a thumb on the lower front side of the ankle joint in subtalar joint and index finger forward to external ankle, the Talus was palpable. Another examiner recorded Navi bumps distance to Earth in millimeters. Then the person in the standing position divided hos weight between the two legs. Again, the Navi prominencewas marked and the height of Navi measured. Navi drooping index is the difference between the height of the Navi in both standing and sitting positions. The test is performed three times and the average of the three scores obtained from the difference between standing and sitting positions as an indicator of the person's Navi dropping. Subjects whose navicular drop index is less than $4 \mathrm{~mm}$ were considered 
supinated (8). In the test, triable's static balance standing on one leg in the center of power, the other leg above the knee flexed and hands are freely in the body. Subjects were looking at a point in front of their eyes two meters far from them. In this situation, the subjects were asked to move least and the center of force plate marked. Postural swings indicators include the mean change in pressure center when standing on one leg as static balance indicator. For dynamic balance test, the index was time to stabilization. For testing, first most vertical jump must be measuredand then; subjects carry out jump-landing protocol for data entry and calculations with 50 percent of the height for calculations of dynamic balance. At a distance of $70 \mathrm{~cm}$ from the center of power on the ground, a point is marked. Participants from behind the dash jump with two legs and after touching the top mark of force plate (which represents $50 \%$ of the maximum jumping height) he comes down with one foot at the center of plate and, once established, puts his hands in the pelvic area, keeps his head up and looks front and tries to maintain his balance. The subjects performed the test several times to become familiar with the conditions and how to run the test. The information about ground reaction forces in two directions of Internal-External and anterior posterior was recorded by the force plate from the moment when the person was in contact with the force plate. This information was stored on a computer device to be used for the analysis. After measuring static and dynamic balance and supinated foot in subjects of both control and experimental groups, the experimental group implemented remedial training for 8 weeks. Training protocol consisted of three sessions per week for eight weeks. There are 48 hours of rest between each exercises and a training session takes about 60 minutes. During this period, the control group were doing their dailyactivities and the overload was applied in practices.

The training program is divided into three parts, including:

1- Warm up

Each session starts with a warm public for ten minutes, including walking slowly - joggingstretching exercise for the whole body and several special moves for lower limb .

The main training run scheduled (a total of 10 short-listed stretch and strengthen muscles weakened, leading to supinated). Stretching exercises are to stretch muscles that includes tibial and (tibialis anterior), and strengthening exercises to strengthen the peroneal muscles (the peroneus longus, peroneus brevis, peroneus). Ten corrective exercises outlined as follows:

1. Walk right (keep your head up and your eyes look straight ahead. Keep your shoulders in line with the rest of the body).Do not disturb the natural movement of the arms when 
walking (the opposite arm and leg). Put your feet in a parallel direction and not to divert around.

2. Swimming on the wall. Stay against the wall so that the wall about a meter away from you.Then both hands to the wall and bend your elbows. Hold this position for 5 seconds. Then move to the first position. The move is in two stages, do 15 repetitions. Rest 30 seconds between each set.

3. Ankle plantar flexion strength. While sitting on the floor and have long legs, using a belt or strap, loop it around your legs. Then slowly move your feet and toes forward and one back into position. The move twice, each time with 15 repetitions to do.

4. Raise the heel. In the back seat with a backrest like you. Using the chair as a fulcrum to gently lift the toes and heel to move upward. Stay in this position for 5 seconds. Then slowly move downward. The rest is due to the imbalance. The move to two sets of 15 repetitions each set and do. 30 seconds rest between sets.

5. Skip Wall. About a meter above your height on the wall draw a line or a colored tape on the wall.Then, with a jump try to touch the spot marked by hand, landing lightly on the toe while landing. The move to two sets of 15 repetitions each set.

6. Stand on the inner edge of the foot.

7. Using an elastic yarn or cache, loop it around your foot and then the free end rather than close it, open it in the move towards the inside of the ankle. Then slowly move your ankle to the outside of the body to create resistance, then back to the first position. The move is in two stages, with 15 repetitions.

8. Put one foot on a height. Must be 7 to $12 \mathrm{~cm}$ height. Other feet flat on the floor. Then your weight on the leg that is in height and make up the other end. Move it slowly prompts two stages, with 15 repetitions.

9. Stand on the ramp, so that the foot plantar flexion to go hand against the wall to avoid losing balance. Move it until you feel a stretch in the leg. Stretch for 15 to 30 seconds then return to the first position 0.3 times.

10.The balance on one leg. Without the use of supports on one leg for 30 seconds and repeat 3 times. Do this exercise with your eyes open. After a while, try this exercise with your eyes closed. When on both master mode, try to do this exercise on a pillow. 


\section{2- Cool Down.}

Measurement devices: Caliper Model Yagamy Japan

Page $40 * 60 * 7 \mathrm{~cm}$ British troops

Footrest board $30 * 20 * 10 \mathrm{~cm}$

Tape measure

Spss software version 21

\section{RESULTS:}

Demographic characteristics of subjects in the control and experimental groups presented in table 1 Results of physical characteristics such as height, weight, age, static balance, dynamic balance, supinated As a result, the homogeneity of the two groups after randomization Groups.

Table 1. Average individual characteristics of subjects in the pretest

\begin{tabular}{|c|c|c|c|c|c|c|c|c|}
\hline Variable & $\begin{array}{l}\text { Abunda } \\
\text { nce }\end{array}$ & $\begin{array}{l}\text { Age } \\
\text { )year( }\end{array}$ & $\begin{array}{l}\text { height } \\
\text { )cm( }\end{array}$ & $\begin{array}{l}\text { weigh } \\
\mathrm{t} \\
) \mathrm{kg}(\end{array}$ & $\begin{array}{l}\text { Static } \\
\text { balance } \\
\text { )cop( }\end{array}$ & $\begin{array}{l}\text { Dynamic } \\
\text { balance } \\
\text { Anterior- } \\
\text { posterior }\end{array}$ & $\begin{array}{l}\text { Dynamic } \\
\text { balance } \\
\text { Side- } \\
\text { Central }\end{array}$ & $\begin{array}{l}\text { Supinat } \\
\text { ed } \\
(\mathrm{mm}) \\
\text { foot }\end{array}$ \\
\hline $\begin{array}{l}\text { experim } \\
\text { ental } \\
\text { group }\end{array}$ & 10 & $\begin{array}{l}4 \pm 3 / 7 \\
22 /\end{array}$ & $\begin{array}{l}/ 2 \pm 5 / 2 \\
174\end{array}$ & $\begin{array}{l}6 \pm 4 / 5 \\
66 /\end{array}$ & $\begin{array}{l} \pm 1 / 041 \\
4 / 096\end{array}$ & $1 / 69 \pm / 305$ & $2 / 51 \pm / 55$ & $\begin{array}{l}/ 11 \pm / 62 \\
2\end{array}$ \\
\hline $\begin{array}{l}\text { control } \\
\text { group }\end{array}$ & 10 & $\begin{array}{l}8 \pm 3 / 1 \\
21 /\end{array}$ & $\begin{array}{l}/ 1 \pm 4 / 8 \\
175\end{array}$ & $\begin{array}{l}8 \pm 4 / 3 \\
67 /\end{array}$ & $\begin{array}{l} \pm 1 / 334 \\
3 / 984\end{array}$ & $\begin{array}{l}/ 692 \pm / 318 \\
1\end{array}$ & $2 / 47 \pm / 507$ & $\begin{array}{l}/ 14 \pm / 66 \\
2\end{array}$ \\
\hline
\end{tabular}

Independent sample $t$ test with significance level of $p<0.05$ was considered

In comparison of subjects in the control and experimental groups, there was no significant difference in static balance $(\mathrm{p}=0.00)$, and navicular drop $(\mathrm{p}=0.008)$ has been reduced. However, in time to stabilization in the anterior-posterior change significantly $(\mathrm{p}=0.2)$ there weren't a significant difference. 
Table 2. Comparison of static, dynamic balance and supinated foot in experimental and control groups

\begin{tabular}{|l|l|l|l|}
\hline exercise group vs. control & Mean difference & T value & P value \\
\hline Static balance cop & $-1 / 662$ & ${ }^{*}-2 / 82$ & $0 / 011$ \\
\hline Time to establishment & $-0 / 837$ & ${ }^{* *}-2 / 999$ & $0 / 008$ \\
\hline Degree of supinated foot & $-0 / 636$ & ${ }^{* *} 4 / 37$ & $0 / 00$ \\
\hline $\begin{array}{l}\text { Time to stabilization in the anterior- } \\
\text { posterior }\end{array}$ & $-0 / 086$ & ${ }^{n s}-1 / 331$ & $0 / 2$ \\
\hline
\end{tabular}

**: Significant at $99 \%$ level $*$ significant at $95 \%$, ns: not significant

In order to determine better the impact of changes in the navicular drop on improving the balance of the Pearson correlation test was used and the results showed changes navicular by changing the equilibrium level both in static and in dynamic mode (M-L \& AP) significant relationship and the navicular drop below the balance level increased (table 3).

Table 3. Relationship between the navicular changes with changes in static and dynamic balance

\begin{tabular}{|c|c|c|c|c|c|c|}
\hline \multicolumn{2}{|c|}{$\begin{array}{c}\text { Changes in dynamic } \\
\text { balance (A-P) }\end{array}$} & \multicolumn{2}{|c|}{$\begin{array}{c}\text { Changes in dynamic } \\
\text { balance (M-L) }\end{array}$} & \multicolumn{2}{|c|}{ Changes in static balance } & Correlation \\
\hline $\mathrm{r}$ & $\mathrm{P}$ & $\mathrm{r}$ & $\mathrm{P}$ & $\bar{r}$ & $\bar{P}$ & Changes in \\
\hline${ }^{* *}-0.610$ & 0.004 & -0.717 & 0.00 & -0.0648 & 0.002 & navicular \\
\hline
\end{tabular}

**: Significant at $99 \%$ level * significant at $95 \%$, ns: not significant

As the results in Table 3 indicate, reducing the amount of navicular drop has a strong relationship with increasing levels of balance and even though the changes and improvements in the anteriorposterior dynamic balance was not significant, the changes registered with the navicular drop changes correlated.

\section{DISCUSSION}

The aim of this study was to evaluate the eight-week corrective exercises to improve static and dynamic balance in the supinated. (18). Athletes who have better postural sway the possibility of ankle injuries in sports seasons are less (22). 
Postural control, is coordination complex biomechanical information, sensory and muscle effort against external forces $(27,28)$. Dynamic stability provides basic protection against joint damage, and time to stabilization indicator of dynamic balance is dynamic stability in the jump - landing assessment (21). Time to stabilization during the descent, the length of time that your body's center of balance in the reconstruction of the reliance.An increase in muscle contraction reaction time due to mechanical malfunction causes the receptors open and the muscles around the joint beyond the normal range of motion of the ankle joint (Twin fibula) can't be activated quickly.Time to stabilization during the descent, is the length of time that your body's center of balance in the reconstruction of the reliance.Due to the anatomical structure of the foot and its placement in the lowest part of the lower extremity kinetic chain and a relatively small base of support and balance the body on it, it seems logical that any biomechanical changes affect the level of reliance on postural control (20).Therefore, musculoskeletal abnormalities in the lower extremities affects the biomechanics of human movement. It is believed that your feet will depend on the type and shape of the leg (26).Swing over to the inside or outside of the leg may affect the input information from somatosensory $(24,25)$. Swing too stepped outside may not conform enough to the ground, as a result of musculoskeletal structures around the joint happens in order to increase balance and postural stability (25). It is said that hollow leg and foot turned out in the conventional pronated foot gives less sensory information (24).On the other hand when the Subtalar joint pronation can't do pronationfeet can't do shock absorption in the heel to facilitate the construction and normal operation.So exercises that improve these abnormalities, and make the shape and condition of feet as much as possible close to normal, could be effective in improvement of input information from thesole of the foot and ankle in response to surface disturbances and external forces, and thus increase the level ofbalance. The results of data analysis generally refers to the usefulness of training. The results of our research findings are in line with moon and colleagues (2014), who examine the impact of a series of short exercises and correction of dynamic balance and correct the abnormalities had been pronated foot. The results also were in line with the findings of Singh Bal et al. (17) on the impact of progressive exercises to improve dynamic balance. Rothermel et.al showed that when participations were forced to increase their interior arc of feet, they experienced enhancement in their balance, which is in turn in line with our study results. There are limitations in this study, such as the lack of daily control on exercise of control group and the level of participations' motivation. 


\section{Research limitations}

Lack of control in daily activities of control group

The motivation of the participants while participating in practice and test

\section{Suggestions}

The exercises presented in this study can be used to improve the static balance in subjects with abnormalities.

The exercises presented in this study can be used to improve the dynamic balance in subjects with abnormalities.

The exercises presented in this study can be used to improve dynamic balance in people with foot malformations.

\section{CONCLUSION}

The findings showed that Eight-week exercise in people with supinated foot malformations can improve the level of static and dynamic balance and reduce the amount of foot deformity. Therefore implementation of this type of training can also improve static and dynamic balance, reduce the amount of abnormalities in people with supinated foot. Because supinated foot compared to usual mechanical structure of the foot, leads more to less sensory information ankle injury and damage to the knee, and when the joint pronation doesn't do pronation, Subtalar joint under normal mechanism can't facilitate shock absorption in the heel.Conducing the exercises caused the abnormalities to improve and made the shape and condition of feet as much as possible closer to normal. So this exercise led to the information received from the sole of the foot, and as a result an increase in balance level occurred in participations.

\section{ACKNOWLEDGMENTS}

This paper is resulting from the thesis of master's degrees, the code is adopted by the Islamic Azad University of Karaj. We appreciate professors and all those who helped me in every stage of this study.

\section{REFERENCES}

1. Khaleghi, M., et al compared time to stabilization in pronated foot deformities with an emphasis on sensory information, 2008. 
2. Fakoor Rashid Hussain H. The effect of a 6-week program on improving flat foot and static balance boys 10-12 Salh.payan a Master of University of Guilan, 2013.

3. Daneshmandi et al, Sports Corrective Exercises The University of Guilan, 2010.

4. Kendall Florence Peterson et al. Review and evaluate the performance of postural muscles and pain translator Alireza Everlasting Everlasting publications, 2004.

5. Balasubramaniam, R. and Wing, A. M. The dynamics of standing balance. TRENDS in Cognitive Sciences, 2002, 6(12) : 531-536.

6. Barton CJ Bonanno D, Levinger P, Menz HB. Foot and ankle characteristics in patellofemoral pain syndrome : a case control and reliability study . The J Orthopaed sports Phys Therap 2010,40(5):286-96.

7. Neely FG . Biomechanical risk factors for exercise related lower injuries . sports med 1998;26(6):395-413.

8. Brody, D. Techniques in the evaluation and treatment of the injuredrunner. Orthop Clin North Am. 1982, 13:542-558.

9. Cornwall, MW. Murrell, PM. Postural swary following inversion sprain of ankle.J AM Podiater Med A ssoc, 1991, 81:243-247.

10. Gopalai, A. A., Senanayake S. M. N.A, and Gouwanda, D. Determining level of postural control in young adults using force-sensing resistors. IEEE Transactions On Information Technology In Biomedicine, 2011, 15(4) : 608-614.

11. Guskiewicz, K, Perrin, D. Research and clinical applications of assessing balance. Sport Rehabil. 1996, 5 :45-63.

12. Marsh, D.W., Richard, L.A., Williams, L.A., Linch, K.J . The relationship between balance and pitching in college baseball pitcher. J strength Con Res. 2004, 18: 441-56.

13. McPoil, T.G, Cornwall, M.W. The relationship between static lower extremity measurements and rearfoot motion during walking. J Orthop Sports Phys Ther. 1996, 24:309 -314.

14. Razeghi Mand, Batt, ME. Foot type classifeation : acritcal review of current methods .gait and posture 2004, 15:288-291.

15. Williams, D.S., McClay, I.S. Measurements used to characterize the foot and the medial longitudinal arch: reliability and validity. Phys Ther. 2000, 80:864-871.

16. Rothermel, SA, Hale, SA, Hertel J, and Denegar CR. Effect of activefoot positioning on the outcome of a balance training program. PhysTher Sport 2004, 5: 98-103. 
17. Singh Bal, B. Effect of High Volume versus Low Volume Balance Training on Static and Dynamic Balance. International Journal of Sports Science and Engineering 2012, 06(1):9-16.

18. Wikstrom, E. A ,Tillman, M.D, Smith, A .N, Borsa, P.A. A new force plate technology measure of dynamic postural stability : The dynamic postural stability index.J Athl Train. 2005, 40(4):305-309.

19. Delecluse, C, Roelants, M, verschueren, S. Strength increase after wole body vibration compared with resistance training. Med Sci sports Exe. 2003, 12: 1033-41.

20. Gupta, D., \& Nair, M. D. Neurogenic orthostatic hypotension: Chasing "the fall". Postgraduate Medical Journal, 2008, 84: 6-14.

21. Karimi N, Ebrahimi E, Kahrizi S, Torkaman G. Reliability of postural balance evaluation using the biodex balance system in subjects with and without low back pain. JPMI; 2008, 22: 95-101. (Persian).

22. Myer, GD, Ford, KR, Brent, JL, and Hewett, TE. The effects of plyometric vs. dynamic stabilization and balance training on power, balance, and landing force in female athletes. $\mathrm{J}$ Strength Cond Res 2006, 20: 345-353.

23. Robert, W., Aron, J., Mark, L. The effect of plyometric training on distance running performance. Eur J Appl Physiol. 2003, 89: 1-7.

24. Ross, S. E. and Guskiewicz, K. M. Examination of static and dynamic postural stability in individuals with functionally stable and unstable ankles. Clin J Sport Med 2004, 14: 332-338.

25. Schmitz, R.J., Kulas, A.S., Perrin, D.H., Riemann, B.L., Shultz, S.J. Sex differences in lower extremity biomechanics during single leg landings. Clin Biomech. 2007, 22:681-688.

26. Shumway-Cook, A., Woollacott, M.H. Motor control: Theory and Practical Applications. 1st ed. Baltimore, MD: Williams \& Wilkins. 1995, 119-142.

27. Torvinen, S, kannus, P, Sievanen, H., Tero, A., Pasanen, M., Teppo, L., Oja, P., Vuori, J. Effect of four-month vertical whole body vibration on performance and balance. Med Sci Sports Exe. 2002, 34(9), 1523-28examine the effect of 8week reform exercises on the improvement of the balance of static and dynamic supinated foot

\section{How to cite this article:}

Mehrian M M, Sarshin A, Rostamkhani H. Effect of 8-week exerciseon improving the static and dynamic balance of supinated foot. J. Fundam. Appl. Sci., 2016, 8(3S), 1246-1256. 